Board of Governors of the Federal Reserve System

International Finance Discussion Papers

Number 621

September 1998

\title{
RATIONAL BUBBLES UNDER DIVERSE INFORMATION
}

\author{
Dahai $\mathrm{Yu}$
}

Note: International Finance Discussion Papers are preliminary materials circulated to stimulate discussion and critical comment. References to International Finance Discussion Papers (other than an acknowledgment that the writer has had access to unpublished material) should be cleared with the author or authors. Recent IFDPs are available on the Web at www.bog.frb.fed.us. 


\title{
RATIONAL BUBBLES UNDER DIVERSE INFORMATION
}

\author{
Dahai $\mathrm{Yu}^{*}$
}

\begin{abstract}
This paper uses a set of post-extraction information trees to generally model diverse information and agent specific state price processes to define present and fundamental values. It shows that there can be no negative or finite bubbles and that, if agents are impatient and the aggregate endowment has a finite present value under some state price process of some agent, then there can be no bubble under this state price process for any asset with positive supply.
\end{abstract}

Keywords: bubbles, asset pricing, information.

\footnotetext{
* The author, who is assistant professor of economics, Tufts University, Medford, MA 02155, wrote this paper while he was a consultant in the Division of International Finance, Board of Governors of the Federal Reserve System. The views in this paper are solely the responsibility of the author and should not be interpreted as reflecting the views of the Board of Governors of the Federal Reserve System or of any other person associated with the Federal Reserve System. The author is deeply indebted to David Bowman, whose insight underlies much of Theorem 2, and benefited from discussions with and criticisms from Jon Faust, Dale Henderson, Peter Hooper, Stephen LeRoy, Ralph Tryon, Martin Uribe, Jiang Wang and Michael Woodford. Email: yud@ msn.com.
} 


\section{Introduction}

As usually defined, bubbles are deviations of asset prices from their fundamental values, or the present values of their dividends. There is by now a large body of literature on rational asset price bubbles, including the general treatment by Santos and Woodford (1997), who build on the work of Tirole (1985) and others. The central result of Santos and Woodford is the non-existence of bubbles on assets with positive supply in any equilibrium where the aggregate endowment has a finite present value. Other results include the non-negativity of bubbles and the non-existence of bubbles on finite maturity assets. A restrictive assumption used by Santos and Woodford is the frictionless asset markets. This assumption is relaxed by Yu (1998), who shows that, in the presence of bid-ask spreads and short-sale constraints, the results of Santos and Woodford survive in some similar form.

Another restrictive Santos-Woodford assumption is virtually homogeneous information. While differing probabilities that agents attach to events will not render their arguments invalid, more substantial information diversity will. Specialized studies of bubbles under diverse information include Allen and Gorton (1993), who show that bubbles on a short-sale constrained asset can occur as a result of the information asymmetry between a principal and an agent, and Allen, Morris and Postlewaite (1993), who show that a short-sale constrained asset known to be worthless by all agents individually may nonetheless command a positive equilibrium price if agents do not know of each other's information. The noise

trader models, such as that of De Long et al. (1990) also address diverse information, as do the learning models such as those of Wang (1993) and Zhou (1995), which is summarized in Chow (1997). 
This paper treats bubbles under diverse information at a level of generality comparable to Santos and Woodford (1997). We model diverse information by a set of post-extraction information trees. In rational expectations models, it is standard to assume that agents are capable of extracting information from all the variables they can observe. Since our focus is on the theory, we abstract from the details of the extraction process and focus on the postextraction information structure. The use of post-extraction information trees requires that all commonly observed variables (common observables) be adapted to each agent's information tree. We assume that prices and payoffs, which figure prominently in any discussion of bubbles, are among the common observables. This most natural assumption implies that a good deal of information is necessarily revealed by the market, and our basic conclusion is that any remaining information diversity matters little as far as the existence of bubbles is concerned, and the Santos-Woodford results need hardly any modification.

Here is a brief summary of the paper. Section 2 describes the information structure and introduces a system of notation that can be used to relate nodes on different trees. It introduces $\mathrm{N}$, the join tree or the tree of total information, and $\mathrm{N}^{\mathrm{m}}$, the meet tree or the tree of common knowledge. The information tree of an agent can be regarded as a particular coarsening of $\mathrm{N}$ and a particular refinement of $\mathrm{N}^{\mathrm{m}}$. By the no extraction condition, prices, dividends and all other common observables must be adapted to $\mathrm{N}^{\mathrm{m}}$.

Section 3 discusses agent specific state price processes and explains the need to use them. It uses an example to show that there may not exist a "state price process" on $\mathrm{N}$ even if no agent can arbitrage. It shows, through Proposition 1 , that, a "state price process" on $\mathrm{N}^{\mathrm{m}}$ generated by a state price process of some agent can usually produce only an average of the 
agent's present values. In addition, some "state price processes" on $\mathrm{N}^{\mathrm{m}}$ may not have clear economic meaning.

Section 4 establishes two nonexistence theorems. Theorem 1 shows that, under any state price process for any agent, bubbles are nonnegative and that no finite maturity asset can have a bubble. Theorem 2 shows that, if agents are impatient and the aggregate endowment has a finite present value under some state price process of some agent, then there is no bubble under this state price process for any asset with positive supply. This seemingly strong result rests on the facts that the market necessarily reveals a good deal of information, and that any state price process of any agent must be consistent with the commonly observed prices and dividends and therefore has some economy-wide significance. In order to value one agent's variables by another agent's state price process, we introduce a system of artificial weights defined on N. Because the aggregate variables are assumed to be adapted to every agent's information tree, the artificial weights drop out as a result of aggregation. Section 5 concludes.

\section{Information Structure}

Consider a discrete-time, infinite-horizon economy inhabited by a finite number of rational, price taking, infinitely lived agents whose information structure is described by a set of information trees defined on a common state space. (The finiteness in the number of agents is not needed; all the results of this paper are valid as long as the number of agent types is finite.) In general, information about the state of nature is revealed to different agents differently, and each agent may have a distinct information tree. Agents are capable of extracting information from all the variables they can observe now and in the future. These include not only variables observable to all agents (common observables), but also variables 
observable to individual or subgroups of agents. The information trees we use are the end result of the extraction processes. Modeling extraction processes can shed light on many issues but is often a difficult undertaking. Since our goal of characterizing price bubbles has little to do with the details of the extraction process, we choose to keep things simple (and general) and make post-extraction information trees our starting point.

Post-extraction information trees are not primitives like preferences, technology, endowments and pre-extraction information trees. Rather, they are equilibrium specific and are similar in this regard to the plans and expectations described by Radner (1972). At least in special cases, one can show that, generically, prices are fully revealing (Radner, 1979). Following the example of Allen, Morris and Postlewaite (1993), we do not address the generic existence of equilibrium with genuinely diverse post-extraction information. Instead, we focus on identifying conditions that any diverse information equilibrium must satisfy.

Nodes of a information tree on a given date form a partition of the states of nature. The join of the individual partitions on a date, which has the "boundaries" of all individual partitions as its boundaries, is the total information revealed to agents up to that date. Connecting the joins on different dates, we get $\mathrm{N}$, the join tree or the tree of total information. The meet of the individual partitions on a date, which has the common boundaries of individual partitions as its boundaries, represents agents' common knowledge, a concept defined by Aumann (1976) and clarified by Milgrom (1981). Connecting the meets on different dates, we get $\mathrm{N}^{\mathrm{m}}$, the meet tree or the tree of common knowledge. The information tree of each agent represents a particular "bundling" of $\mathrm{N}$ and a particular "splitting" of $\mathrm{N}^{\mathrm{m}}$.

When dealing with post-extraction information trees, care must be taken that an agent cannot extract any more information from any of the variables it can observe. As a necessary 
condition for no extraction, all common observables must be adapted to the meet tree. (For further details, see Fudenberg and Tirole, 1991 or Geanakoplos, 1994.) We choose to be noncommittal on whether agents can observe each other's endowments, trades and consumption. While observability of these variables tends to make diverse information disappear, observability of some aggregates of these variables can be consistent with diverse information. Our model is valid under a variety of observability assumptions.

Let $s^{t}$ be a typical node on the join tree $\mathrm{N}$ on date $\mathrm{t}$. Each $\mathrm{s}^{\mathrm{t}}$ has a unique immediate predecessor $\mathrm{s}^{\mathrm{t}}-1$ and a finite number of immediate successors, a typical one of which is denoted by $s^{t+1} \mid s^{t}$. The exceptions are the $\mathrm{N}$ nodes at $\mathrm{t}=0$, which have no predecessors. We use $s^{r} \mid s^{t}$ to indicate that $s^{r}$ belongs to the subtree of $N$ starting at $s^{t}$. That is, $s^{r} \mid s^{t}$ means either $s^{r}$ $=\mathrm{s}^{\mathrm{t}}$ or $\mathrm{s}^{\mathrm{r}}$ is a (not necessarily immediate) successor of $\mathrm{s}^{\mathrm{t}}$.

Similarly, $\alpha^{\mathrm{t}}$ is a typical node on agent $\alpha$ 's information tree $\mathrm{N}^{\alpha}$, and $\mathrm{m}^{\mathrm{t}}$ is a typical node on $\mathrm{N}^{\mathrm{m}}$. The notation for $\mathrm{N}$ applies to $\mathrm{N}^{\alpha}$ and $\mathrm{N}^{\mathrm{m}}$ as well. By definition, each $\mathrm{N}^{\alpha}$ node is composed of one or more $\mathrm{N}$ nodes, and each $\mathrm{N}$ node is in exactly one $\mathrm{N}^{\alpha}$ node. Similarly, each $\mathrm{N}^{\mathrm{m}}$ node is composed of one or more $\mathrm{N}^{\alpha}$ nodes, and each $\mathrm{N}^{\alpha}$ node is in exactly one $\mathrm{N}^{\mathrm{m}}$ node. We use $s^{t} / \alpha^{t}$ to represent an $N$ node in $\alpha^{t}$ and use $\alpha^{t}=s^{t}$ to indicate that $s^{t}$ is the only $\mathrm{N}$ node in $\alpha^{t}$. Let $\beta^{t}$ be a node on agent $\beta$ 's information tree $N^{\beta}$. We use $\alpha^{t}=\beta^{t}$ to indicate that $\alpha^{t}$ and $\beta^{t}$ are the same (i.e., contain the same $\mathrm{N}$ nodes). The expression $\alpha^{\mathrm{t}} / \beta^{\mathrm{t}}$ and those involving $\mathrm{m}^{\mathrm{t}}$ and $\mathrm{N}^{\mathrm{m}}$ have obvious meanings. To take care of the possibility that agents start with different information, we allow multiple $\mathrm{t}=0$ nodes for $\mathrm{N}$ and for individual information trees. We will assume, however, that $\mathrm{N}^{\mathrm{m}}$ has only one $\mathrm{t}=0$ node. 
The number of goods and assets, good and asset prices and asset payoffs in dividends and assets are all common observables. No extraction requires that they be adapted to $\mathrm{N}^{\mathrm{m}}$. There are $n\left(m^{t}\right)$ freely disposable goods at $m^{t}$, with a $1 \times n\left(m^{t}\right)$ nonnegative price vector $p\left(m^{t}\right)$. At each $\mathrm{m}^{\mathrm{t}}$, at least one good has positive price, and this good may be used as the numeraire for $\mathrm{m}^{\mathrm{t}}$ so that all other good and asset prices at $\mathrm{m}^{\mathrm{t}}$ are in reference to the quantity of this numeraire good. The idea that $\mathrm{p}$ is adapted to $\mathrm{N}^{\mathrm{m}}$ on date $\mathrm{t}$ may be so expressed: for any $\mathrm{s}^{\mathrm{t}}$ and any $\mathrm{s}^{\mathrm{t}} / \mathrm{m}^{\mathrm{t}}, \mathrm{p}\left(\mathrm{s}^{\mathrm{t}} / \mathrm{m}^{\mathrm{t}}\right)=\mathrm{p}\left(\mathrm{m}^{\mathrm{t}}\right)$. The expression $\mathrm{p}\left(\mathrm{s}^{\mathrm{t}}\right)$ is meaningful and is equal to the value of $\mathrm{p}$ on the $\mathrm{N}^{\mathrm{m}}$ node that contains $\mathrm{s}^{\mathrm{t}}$. These observations apply to all variables adapted to $\mathrm{N}^{\mathrm{m}}$ or any individual information tree.

There are $\mathrm{k}\left(\mathrm{m}^{\mathrm{t}}\right)$ freely disposable assets at $\mathrm{m}^{\mathrm{t}}$ with price $\mathrm{q}\left(\mathrm{m}^{\mathrm{t}}\right)$, a $1 \times \mathrm{k}\left(\mathrm{m}^{\mathrm{t}}\right)$ vector. At each $\mathrm{m}^{\mathrm{t}}$, the dividends on assets are specified by an $n\left(\mathrm{~m}^{\mathrm{t}}\right) \times \mathrm{k}\left(\mathrm{m}^{\mathrm{t}}-1\right)$ nonnegative matrix $d\left(\mathrm{~m}^{\mathrm{t}}\right)$, and the payoffs of assets in the form of assets are specified by a $k\left(m^{t}\right) \times k\left(m^{t}-1\right)$ nonnegative matrix $b\left(m^{t}\right)$. The nonnegativity of $d\left(m^{t}\right)$ and $b\left(m^{t}\right)$ may be understood as a consequence of free disposal. A portfolio $\mathrm{Z}$ held at the end of trading at node $\mathrm{s}^{\mathrm{t}}-1$ is paid $d\left(\mathrm{~s}^{\mathrm{t}}\right) \mathrm{Z}$ in dividends and $b\left(s^{t}\right) Z$ in assets at $s^{t}$. For $\mathrm{m}^{\mathrm{t}}$ and $\mathrm{m}^{\mathrm{r}} \mid \mathrm{m}^{\mathrm{t}}$, the $\mathrm{k}\left(\mathrm{m}^{\mathrm{r}}\right) \times \mathrm{k}\left(\mathrm{m}^{\mathrm{t}}\right)$ asset transformation matrix $\mathrm{e}\left(\mathrm{m}^{\mathrm{r}} \mid \mathrm{m}^{\mathrm{t}}\right)$ is defined recursively by:

$$
\mathrm{e}\left(\mathrm{m}^{\mathrm{t}} \mid \mathrm{m}^{\mathrm{t}}\right)=\mathrm{I}_{\mathrm{k}\left(\mathrm{m}^{\mathrm{t}}\right)}, \mathrm{e}\left(\mathrm{m}^{\mathrm{r}} \mid \mathrm{m}^{\mathrm{t}}\right)=\mathrm{b}\left(\mathrm{m}^{\mathrm{r}}\right) \mathrm{e}\left(\mathrm{m}^{\mathrm{r}}-1 \mid \mathrm{m}^{\mathrm{t}}\right) \text { for all } \mathrm{m}^{\mathrm{r}} \mid \mathrm{m}^{\mathrm{t}}, \mathrm{r}>\mathrm{t}
$$

Asset $\mathrm{j}$ has finite maturity if there exists a date $\mathrm{R}$ such that $\mathrm{e}_{\mathrm{ij}}\left(\mathrm{m}^{\mathrm{r}} \mid \mathrm{m}^{\mathrm{t}}\right)=0$ for all $\mathrm{i}$, all $\mathrm{r} \geq \mathrm{R}$. The $\mathrm{n}\left(\mathrm{m}^{\mathrm{r}}\right) \times \mathrm{k}\left(\mathrm{m}^{\mathrm{t}}\right)$ dividend matrix $\mathrm{x}\left(\mathrm{m}^{\mathrm{r}} \mid \mathrm{m}^{\mathrm{t}}\right)$ for $\mathrm{m}^{\mathrm{t}}$ and any $\mathrm{m}^{\mathrm{r}} \mid \mathrm{m}^{\mathrm{t}}, \mathrm{r}>\mathrm{s}$, is defined by:

$$
x\left(m^{r} \mid m^{t}\right)=d\left(m^{r}\right) e\left(m^{r}-1 \mid m^{t}\right)
$$

\section{The Need for Agent Specificity}


With the necessary apparatus in place, we begin to discuss the meaning of bubbles. In the case of homogeneous information, absence of arbitrage (of any finite horizon) by one agent implies absence of arbitrage by all agents, and this universal absence of arbitrage is equivalent to the existence of a state price process $\left\{a\left(s^{r}\right)\right\}$ defined on the common information tree $\mathrm{N}$ (Ross, 1976; Yu, 1998). At each $\mathrm{s}^{\mathrm{t}},\left\{\mathrm{a}\left(\mathrm{s}^{\mathrm{r}}\right)\right\}$ satisfies the basic state price relation:

$$
a\left(s^{t}\right) q\left(s^{t}\right)=\sum_{s^{t+1} \mid s^{t}} a\left(s^{t+1}\right)\left[p\left(s^{t+1}\right) d\left(s^{t+1}\right)+q\left(s^{t+1}\right) b\left(s^{t+1}\right)\right]
$$

In addition, any resource process $\left\{x\left(s^{r}\right)\right\}$ is necessarily adapted to $\mathrm{N}$, and its present value at $\mathrm{s}^{\mathrm{t}}$ is defined in terms of $\left\{\mathrm{a}\left(\mathrm{s}^{\mathrm{r}}\right)\right\}$ :

$$
\mathrm{v}_{\mathrm{x}}\left(\mathrm{s}^{\mathrm{t}}, \mathrm{a}\right)=\frac{1}{\mathrm{a}\left(\mathrm{s}^{\mathrm{t}}\right)} \sum_{\mathrm{r}=\mathrm{t}+1}^{\infty} \sum_{\mathrm{s}^{\mathrm{r}} \mid \mathrm{s}^{\mathrm{t}}} \mathrm{a}\left(\mathrm{s}^{\mathrm{r}}\right) \mathrm{p}\left(\mathrm{s}^{\mathrm{r}}\right) \mathrm{x}\left(\mathrm{s}^{\mathrm{r}}\right)
$$

The fundamental value of asset $j$ at $s^{t}$ under $\left\{a\left(s^{r}\right)\right\}, f_{j}\left(s^{t}, a\right)$, is defined as the present value of its dividends. A price bubble is said to exist on asset $j$ at $s^{t}$ under $\left\{a\left(s^{r}\right)\right\}$ if $f_{j}\left(s^{t}, a\right)$ is different from $\mathrm{q}_{j}\left(\mathrm{~s}^{\mathrm{t}}\right)$, asset $\mathrm{j}$ 's price at $\mathrm{s}^{\mathrm{t}}$. When markets are incomplete, the state price process is not unique, and the fundamental value of an asset need not be unique. It is then possible for an asset to exhibit a bubble under one state price process but not under another.

With diverse information, agents have different ideas on what the states are, and state price process and related concepts become agent specific. In place of (3) and (4), we have:

$$
\begin{aligned}
& \mathrm{a}^{\alpha}\left(\alpha^{\mathrm{t}}\right) \mathrm{q}\left(\alpha^{\mathrm{t}}\right)=\sum_{\alpha^{\mathrm{t}+1} \mid \alpha^{\mathrm{t}}} \mathrm{a}^{\alpha}\left(\alpha^{\mathrm{t}+1}\right)\left[\mathrm{p}\left(\alpha^{\mathrm{t}+1}\right) \mathrm{d}\left(\alpha^{\mathrm{t}+1}\right)+\mathrm{q}\left(\alpha^{\mathrm{t}+1}\right) \mathrm{b}\left(\alpha^{\mathrm{t}+1}\right)\right] \\
& \mathrm{v}_{\mathrm{x}}\left(\alpha^{\mathrm{t}}, \mathrm{a}^{\alpha}\right)=\frac{1}{\mathrm{a}^{\alpha}\left(\alpha^{\mathrm{t}}\right)} \sum_{\mathrm{r}=\mathrm{t}+1}^{\infty} \sum_{\alpha^{\mathrm{r}} \mid \alpha^{\mathrm{t}}} \mathrm{a}^{\alpha}\left(\alpha^{\mathrm{r}}\right) \mathrm{p}\left(\alpha^{\mathrm{r}}\right) \mathrm{x}\left(\alpha^{\mathrm{r}}\right)
\end{aligned}
$$

Here $\left\{a^{\alpha}\left(\alpha^{r}\right)\right\}$ is a state price process defined on $\mathrm{N}^{\alpha}$, whose existence is equivalent to the absence of $\alpha$-arbitrage (i.e., arbitrage by agent $\alpha$ ), and $\left\{x\left(\alpha^{r}\right)\right\}$ is a resource process adapted to 
$\mathrm{N}^{\alpha}$, of which any dividend process is an example. The issues to be addressed are whether agent specificity is really needed in the study of bubbles and whether results comparable to those for the homogeneous information case can be derived.

We begin by explaining the need for agent specificity. As the following example shows, even if no agent can arbitrage, a "state price process" on $\mathrm{N}$ need not exist. Consider an economy with two agents $(\alpha$ and $\beta)$ and four states of nature $\left(\omega_{1}, \omega_{2}, \omega_{3}\right.$ and $\left.\omega_{4}\right)$ to be fully revealed on $t=2$. At $t=0$ neither agent has information. At $t=1$, agent $\alpha$ 's information is the partition $\left\{\left(\omega_{1}, \omega_{2}\right),\left(\omega_{3}, \omega_{4}\right)\right\}$, while agent $\beta$ 's information is the partition $\left\{\left(\omega_{1}, \omega_{3}\right),\left(\omega_{2}, \omega_{4}\right)\right\}$. The information trees are shown below.

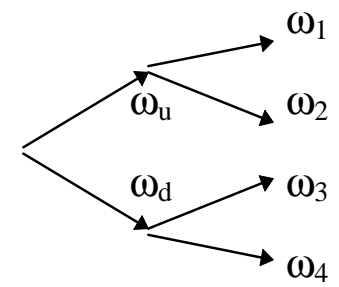

$\mathrm{N}^{\alpha}$

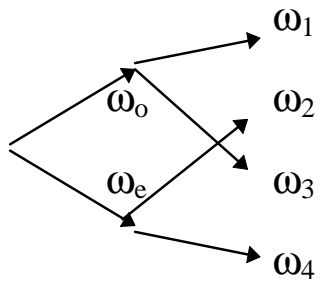

$\mathrm{N}^{\beta}$

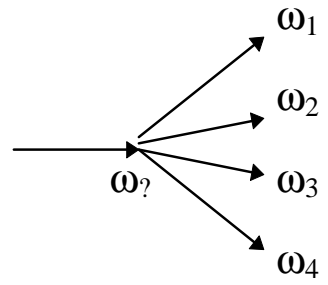

$\mathrm{N}^{\mathrm{m}}$

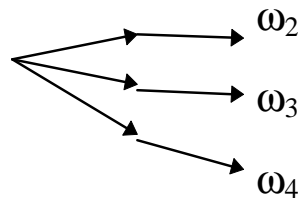

$\mathrm{N}$

We have labeled the nodes $\left(\omega_{1}, \omega_{2}\right)$ and $\left(\omega_{3}, \omega_{4}\right)$ on $\mathrm{N}^{\alpha}$ as $\omega_{\mathrm{u}}(\mathrm{up})$ and $\omega_{\mathrm{d}}($ down), the nodes $\left(\omega_{1}, \omega_{3}\right)$ and $\left(\omega_{2}, \omega_{4}\right)$ on $\mathrm{N}^{\beta}$ as $\omega_{\mathrm{o}}($ odd $)$ and $\omega_{\mathrm{e}}($ even $)$, and the $\mathrm{t}=1$ node on $\mathrm{N}^{\mathrm{m}}$ as $\omega_{\text {? }}$.

The economy has two assets. The price of either asset is 1 on $t=0$ and $t=1$ and zero on $\mathrm{t}=2$. Neither asset pays dividend on $\mathrm{t}=1$. Asset 1 pays a dividend of 1 on $\mathrm{t}=2$, and asset 2's state specific dividends on $\mathrm{t}=2$ are $\mathrm{d}_{1}=\frac{3}{2}, \mathrm{~d}_{2}=\frac{1}{2}, \mathrm{~d}_{3}=\frac{2}{3}$ and $\mathrm{d}_{4}=2$. It is easy to see that neither agent can arbitrage. However, an agent with information tree $\mathrm{N}$ would be able to arbitrage, and so there does not exist a process on $\mathrm{N}$ satisfying state price relation (3). 
We show that, even though the two agents recognize the same nodes on $t=2$, which are also the $\mathrm{N}^{\mathrm{m}}$ nodes on $\mathrm{t}=2$, one agent may find the state prices assigned to these nodes by the other agent unacceptable. The implication is that, in calculating present values, one must in general take into account each agent's state prices. Set any state price assigned to $t=0$ to 1 . It is easy to verify that, for any $\mathrm{a}_{\mathrm{u}}^{\alpha}$ satisfying $0<\mathrm{a}_{\mathrm{u}}^{\alpha}<1,\left\{\mathrm{a}^{\alpha}\right\}=\left\{\mathrm{a}_{\mathrm{u}}^{\alpha}, \mathrm{a}_{\mathrm{d}}^{\alpha}=1-\mathrm{a}_{\mathrm{u}}^{\alpha}, \mathrm{a}_{1}^{\alpha}=\mathrm{a}_{2}^{\alpha}=\right.$ $\left.\frac{1}{2} a_{u}^{\alpha}, a_{3}^{\alpha}=\frac{3}{4}\left(1-a_{u}^{\alpha}\right), a_{4}^{\alpha}=\frac{1}{4}\left(1-a_{u}^{\alpha}\right)\right\}$ is a valid set of state prices for agent $\alpha$, and this expression yields all the valid $\left\{a^{\alpha}\right\}$ 's as $a_{u}^{\alpha}$ covers the open interval $(0,1)$. Similarly, with $a_{o}^{\beta}$ covering the open interval $(0,1),\left\{a^{\beta}\right\}=\left\{a_{o}^{\beta}, a_{e}^{\beta}=1-a_{o}^{\beta}, a_{1}^{\beta}=\frac{2}{5} a_{o}^{\beta}, a_{2}^{\beta}=\frac{2}{3}\left(1-a_{o}^{\beta}\right), a_{3}^{\beta}=\right.$ $\left.\frac{3}{5} a_{o}^{\beta}, a_{4}^{\beta}=\frac{1}{3}\left(1-a_{o}^{\beta}\right)\right\}$ yields all the valid $\left\{a^{\beta}\right\}$ 's. One such $\left\{a^{\beta}\right\}$ (with $\left.a_{o}^{\beta}=\frac{1}{2}\right)$ is $a_{1}^{\beta}=\frac{1}{5}$, $a_{2}^{\beta}=\frac{1}{3}, a_{3}^{\beta}=\frac{3}{10}$, and $a_{4}^{\beta}=\frac{1}{6}$, which agent $\alpha$, who always has $a_{1}^{\alpha}=a_{2}^{\alpha}$, finds unacceptable.

In this example, the hypothetical agent with information tree $\mathrm{N}$ is better informed than either agent $\alpha$ or agent $\beta$. It is therefore not surprising that it can arbitrage when agents $\alpha$ and $\beta$ cannot; this is the "advantage of better information" discussed more generally by Duffie and Huang (1986). By the same reasoning, a hypothetical agent with information tree $\mathrm{N}^{\mathrm{m}}$ will not be able to arbitrage and a process on $\mathrm{N}^{\mathrm{m}}$ that satisfies the state price relation must exist as long as some agent cannot arbitrage. One may then wonder whether it is enough to use only the "state price processes" on $\mathrm{N}^{\mathrm{m}}$ and not those for individual agents. The following proposition gives a generally negative answer. Let $\left\{\mathrm{a}^{\alpha}\right\}$ be a state price process for agent $\alpha$, and let $\left\{x\left(m^{r}\right)\right\}$ be a resource process adapted to $N^{m}$. We show that $\left\{a^{\alpha}\right\}$ can generate a "state price 
process" on $\mathrm{N}^{\mathrm{m}}$, and the present values of $\left\{\mathrm{x}\left(\mathrm{m}^{\mathrm{r}}\right)\right\}$ under $\left\{\mathrm{a}^{\alpha}\right\}$ and under $\left\{\mathrm{a}^{\mathrm{m}}\right\}$ are related. But the relation is not strong enough to allow us to drop all reference to $\left\{\mathrm{a}^{\alpha}\right\}$.

Proposition 1: Let $\left\{a^{\alpha}\left(\alpha^{r}\right)\right\}$ be an arbitrary state price process for agent $\alpha$.

$$
\begin{aligned}
& \text { (A) }\left\{\mathrm{a}^{\mathrm{m}}\left(\mathrm{m}^{\mathrm{r}}\right)\right\}=\left\{\sum_{\alpha^{\mathrm{r}} / \mathrm{m}^{\mathrm{r}}} \mathrm{a}^{\alpha}\left(\alpha^{\mathrm{r}}\right)\right\} \text { is a process satisfying, at each } \mathrm{m}^{\mathrm{t}} \text {, } \\
& \mathrm{a}^{\mathrm{m}}\left(\mathrm{m}^{\mathrm{t}}\right) \mathrm{q}\left(\mathrm{m}^{\mathrm{t}}\right)=\sum_{\mathrm{m}^{\mathrm{t}+1} \mid \mathrm{m}^{\mathrm{t}}} \mathrm{a}\left(\mathrm{m}^{\mathrm{t}+1}\right)\left[\mathrm{p}\left(\mathrm{m}^{\mathrm{t}+1}\right) \mathrm{d}\left(\mathrm{m}^{\mathrm{t}+1}\right)+\mathrm{q}\left(\mathrm{m}^{\mathrm{t}+1}\right) \mathrm{b}\left(\mathrm{m}^{\mathrm{t}+1}\right)\right]
\end{aligned}
$$

(B) Let $\left\{\mathrm{x}\left(\mathrm{m}^{\mathrm{r}}\right)\right\}$ be an arbitrary resource process adapted to $\mathrm{N}^{\mathrm{m}}$. For each $\mathrm{m}^{\mathrm{t}}$, we have:

$$
\sum_{\alpha^{t} / m^{t}} a^{\alpha}\left(\alpha^{t}\right) v_{x}\left(\alpha^{t}, a^{\alpha}\right)=a^{m}\left(m^{t}\right) v_{x}\left(m^{t}, a^{m}\right)
$$

Proof: For any $\mathrm{m}^{\mathrm{t}}$ and any $\alpha^{\mathrm{t}} / \mathrm{m}^{\mathrm{t}}$, we have, by (5),

$$
a^{\alpha}\left(\alpha^{t} / m^{t}\right) q\left(\alpha^{t}\right)=\sum_{\alpha^{t+1} \mid\left(\alpha^{t} / m^{t}\right)} a^{\alpha}\left(\alpha^{t+1}\right)\left[p\left(\alpha^{t+1}\right) d\left(\alpha^{t+1}\right)+q\left(\alpha^{t+1}\right) b\left(\alpha^{t+1}\right)\right]
$$

Summing (9) over $\alpha^{\mathrm{t}} / \mathrm{m}^{\mathrm{t}}$ and noting that $\mathrm{p}, \mathrm{d}, \mathrm{q}$ and $\mathrm{b}$ are all adapted to $\mathrm{N}^{\mathrm{m}}$, we get:

$$
\begin{aligned}
& {\left[\sum_{\alpha^{t} / \mathrm{m}^{t}} \mathrm{a}^{\alpha}\left(\alpha^{\mathrm{t}}\right)\right] \mathrm{q}\left(\mathrm{m}^{\mathrm{t}}\right)=\sum_{\alpha^{\mathrm{t} / \mathrm{m}^{t}}} \sum_{\alpha^{\mathrm{t}+1} \mid \alpha^{\mathrm{t}}} \mathrm{a}^{\alpha}\left(\alpha^{\mathrm{t}+1}\right)\left[\mathrm{p}\left(\alpha^{\mathrm{t}+1}\right) \mathrm{d}\left(\alpha^{\mathrm{t}+1}\right)+\mathrm{q}\left(\alpha^{\mathrm{t}+1}\right) \mathrm{b}\left(\alpha^{\mathrm{t}+1}\right)\right]} \\
& =\sum_{\mathrm{m}^{\mathrm{t}+1} \mid \mathrm{m}^{\mathrm{t}}} \sum_{\alpha^{\mathrm{t}+1} / \mathrm{m}^{\mathrm{t}+1}} \mathrm{a}^{\alpha}\left(\alpha^{\mathrm{t}+1}\right)\left[\mathrm{p}\left(\alpha^{\mathrm{t}+1}\right) \mathrm{d}\left(\alpha^{\mathrm{t}+1}\right)+\mathrm{q}\left(\alpha^{\mathrm{t}+1}\right) \mathrm{b}\left(\alpha^{\mathrm{t}+1}\right)\right] \\
& =\sum_{\mathrm{m}^{\mathrm{t}+1} \mid \mathrm{m}^{\mathrm{t}}}\left[\sum_{\alpha^{t+1} / \mathrm{m}^{t+1}} \mathrm{a}^{\alpha}\left(\alpha^{\mathrm{t}+1}\right)\right]\left[\mathrm{p}\left(\mathrm{m}^{\mathrm{t}+1}\right) \mathrm{d}\left(\mathrm{m}^{\mathrm{t}+1}\right)+\mathrm{q}\left(\mathrm{m}^{\mathrm{t}+1}\right) \mathrm{b}\left(\mathrm{m}^{\mathrm{t}+1}\right)\right]
\end{aligned}
$$

The equivalence between $\sum_{\alpha^{t} / \mathrm{m}^{t}} \sum_{\alpha^{t+1} \mid \alpha^{t}}$ and $\sum_{\mathrm{m}^{+1+} \mid \mathrm{m}^{t}} \sum_{\alpha^{t+1} / \mathrm{m}^{t+1}}$ follows from the observation that each double summation sums over all $\mathrm{N}^{\alpha}$ nodes at $\mathrm{t}+1$ whose date $\mathrm{t}$ predecessors are in $m^{t} .(10)$ is the same as (7).

(B) For any $\mathrm{m}^{\mathrm{t}}$, 


$$
\begin{aligned}
& \sum_{\alpha^{\mathrm{t} / \mathrm{m}^{\mathrm{t}}}} \mathrm{a}^{\alpha}\left(\alpha^{\mathrm{t}}\right) \mathrm{v}_{\mathrm{x}}\left(\alpha^{\mathrm{t}}, \mathrm{a}^{\alpha}\right)=\sum_{\alpha^{\mathrm{t}} / \mathrm{m}^{\mathrm{t}}} \sum_{\mathrm{r}=\mathrm{t}+1}^{\infty} \sum_{\alpha^{\mathrm{r}} \mid \alpha^{\mathrm{t}}} \mathrm{a}^{\alpha}\left(\alpha^{\mathrm{r}}\right) \mathrm{p}\left(\alpha^{\mathrm{r}}\right) \mathrm{x}\left(\alpha^{\mathrm{r}}\right) \\
& =\sum_{\mathrm{r}=\mathrm{t}+1}^{\infty} \sum_{\mathrm{m}^{\mathrm{r}} \mid \mathrm{m}^{\mathrm{t}}} \sum_{\alpha^{\mathrm{r}} / \mathrm{m}^{\mathrm{r}}} \mathrm{a}^{\alpha}\left(\alpha^{\mathrm{r}}\right) \mathrm{p}\left(\alpha^{\mathrm{r}}\right) \mathrm{x}\left(\alpha^{\mathrm{r}}\right)=\sum_{\mathrm{r}=\mathrm{t}+1}^{\infty} \sum_{\mathrm{m}^{\mathrm{r}} \mid \mathrm{m}^{\mathrm{t}}}\left[\sum_{\alpha^{\mathrm{r}} / \mathrm{m}^{\mathrm{r}}} \mathrm{a}^{\alpha}\left(\alpha^{\mathrm{r}}\right)\right] \mathrm{p}\left(\mathrm{m}^{\mathrm{r}}\right) \mathrm{x}\left(\mathrm{m}^{\mathrm{r}}\right) \\
& =\sum_{\mathrm{r}=\mathrm{t}+1}^{\infty} \sum_{\mathrm{m}^{\mathrm{r}} \mid \mathrm{m}^{\mathrm{t}}} \mathrm{a}^{\mathrm{m}}\left(\mathrm{m}^{\mathrm{r}}\right) \mathrm{p}\left(\mathrm{m}^{\mathrm{r}}\right) \mathrm{x}\left(\mathrm{m}^{\mathrm{r}}\right)=\mathrm{a}^{\mathrm{m}}\left(\mathrm{m}^{\mathrm{t}}\right) \mathrm{v}_{\mathrm{x}}\left(\mathrm{m}^{\mathrm{t}}, \mathrm{a}^{\mathrm{m}}\right)
\end{aligned}
$$

The equivalence between $\sum_{\alpha^{\mathrm{t}} / \mathrm{m}^{\mathrm{t}}} \sum_{\mathrm{r}=\mathrm{t}+1}^{\infty} \sum_{\alpha^{\mathrm{r}} \mid \alpha^{\mathrm{t}}}$ and $\sum_{\mathrm{r}=\mathrm{t}+1}^{\infty} \sum_{\mathrm{m}^{\mathrm{r}} \mid \mathrm{m}^{\mathrm{t}}} \sum_{\alpha^{\mathrm{r}} / \mathrm{m}^{\mathrm{r}}}$ follows from the observation that each triple summation sums over all $\mathrm{N}^{\alpha}$ nodes from $\mathrm{t}+1$ on whose date $\mathrm{t}$ predecessors are in $\mathrm{m}^{\mathrm{t}}$. Q.E.D.

By Proposition 1, if $\alpha^{t} / m^{t}=m^{t}$, we have $a^{\alpha}\left(\alpha^{t} / m^{t}\right)=a^{m}\left(m^{t}\right)$ and $v_{x}\left(\alpha^{t}, a^{\alpha}\right)=v_{x}\left(m^{t}, a^{m}\right)$. In general, however, we know only that $\mathrm{v}_{\mathrm{x}}\left(\mathrm{m}^{\mathrm{t}}, \mathrm{a}^{\mathrm{m}}\right)$ is an $\mathrm{a}^{\alpha}\left(\alpha^{\mathrm{t}} / \mathrm{m}^{\mathrm{t}}\right)$-weighted average of the $\mathrm{v}_{\mathrm{x}}\left(\alpha^{\mathrm{t}} / \mathrm{m}^{\mathrm{t}}, \mathrm{a}^{\alpha}\right)$ 's. As a result, even if we know that the "fundamental value" of an asset under $\left\{a^{m}\right\}$ is equal to its price at $m^{t}$, we cannot be sure that agent $\alpha$ perceives no bubble under $\mathrm{a}^{\alpha}\left(\alpha^{\mathrm{r}}\right)$ at every $\alpha^{\mathrm{t}} / \mathrm{m}^{\mathrm{t}}$.

There is another problem with using the $\left\{a^{m}\right\}$ 's in studying bubbles. Any $\left\{a^{m}\right\}$ generated by some $\left\{\mathrm{a}^{\alpha}\right\}$ has clear economic meaning. It is possible, however, for some $\left\{\mathrm{a}^{\mathrm{m}}\right\}$ satisfying (7) not to be generated by a state price process of some agent. In the example above, (7) becomes $a_{?}^{m}=1, \frac{3}{2} a_{1}^{m}+\frac{1}{2} a_{2}^{m}+\frac{2}{3} a_{3}^{m}+2 a_{4}^{m}=1$ and $a_{1}^{m}+a_{2}^{m}+a_{3}^{m}+a_{4}^{m}=1$. It is easy to verify that $a_{1}^{m}=\frac{1}{3}, a_{2}^{m}=\frac{1}{6}, a_{3}^{m}=\frac{7}{16}$ and $a_{4}^{m}=\frac{1}{16}$ satisfy these conditions. However, this $\left\{\mathrm{a}^{\mathrm{m}}\right\}$ cannot be generated by any $\left\{\mathrm{a}^{\alpha}\right\}$, which necessarily assigns the same state price for $\omega_{1}$ and $\omega_{2}$, or any $\left\{a^{\beta}\right\}$, which necessarily assigns state prices for $\omega_{1}$ and $\omega_{3}$ at two- 
to-three ratio. The implication is that (7) may give rise to $\left\{\mathrm{a}^{\mathrm{m}}\right\}$ 's that do not have clear economic meaning, and to identify the $\left\{\mathrm{a}^{\mathrm{m}}\right\}$ 's that do, we still need to make use of agent specific state price processes.

\section{Two Nonexistence Theorems}

Having explained the need to use agent specific state price processes and related concepts, we now turn to the derivation of results. The $1 \times \mathrm{k}\left(\alpha^{\mathrm{t}}\right)$ fundamental value vector $\mathrm{f}^{\alpha}\left(\alpha^{\mathrm{t}}\right.$, $\left.a^{\alpha}\right)$ for agent $\alpha$ at $\alpha^{t}$ under $\left\{a^{\alpha}\right\}$ is defined as:

$$
\mathrm{f}^{\alpha}\left(\alpha^{\mathrm{t}}, \mathrm{a}^{\alpha}\right)=\frac{1}{\mathrm{a}^{\alpha}\left(\alpha^{\mathrm{t}}\right)} \sum_{\mathrm{r}=\mathrm{t}+1}^{\infty} \sum_{\alpha^{\mathrm{r}} \mid \alpha^{\mathrm{t}}} \mathrm{a}^{\alpha}\left(\alpha^{\mathrm{r}}\right) \mathrm{p}\left(\alpha^{\mathrm{r}}\right) \mathrm{x}\left(\alpha^{\mathrm{r}} \mid \alpha^{\mathrm{t}}\right)
$$

The study of bubbles boils down to comparing $\mathrm{f}^{\alpha}$ with asset price $\mathrm{q}$. The theorem

below, which is essentially the same as the results in Santos and Woodford (1997), shows that negative and finite bubbles cannot exist.

Theorem 1: For any agent $\alpha$, at any node $\alpha^{\mathrm{t}}$ and for any $\left\{\mathrm{a}^{\alpha}\right\}$,

$$
\text { (A) } q\left(\alpha^{t}\right) \geq f^{\alpha}\left(\alpha^{t}, a^{\alpha}\right)
$$

(B) For any asset $\mathrm{j}$ with finite maturity,

$$
\begin{gathered}
\mathrm{q}_{j}\left(\alpha^{\mathrm{t}}\right)=\mathrm{f}_{j}^{\alpha}\left(\alpha^{\mathrm{t}}, \mathrm{a}^{\alpha}\right) \\
\left(\text { C) } \mathrm{a}^{\alpha}\left(\alpha^{\mathrm{t}}\right)\left[\mathrm{q}\left(\alpha^{\mathrm{t}}\right)-\mathrm{f}^{\alpha}\left(\alpha^{\mathrm{t}}, \mathrm{a}^{\alpha}\right)\right]=\sum_{\alpha^{\mathrm{t}+1} \mid \alpha^{\mathrm{t}}} \mathrm{a}^{\alpha}\left(\alpha^{\mathrm{t}+1}\right)\left[\mathrm{q}\left(\alpha^{\mathrm{t}+1}\right)-\mathrm{f}^{\alpha}\left(\alpha^{\mathrm{t+1}}, \mathrm{a}^{\alpha}\right)\right] \mathrm{b}\left(\alpha^{\mathrm{t+1}}\right)\right.
\end{gathered}
$$

Proof: For any $\mathrm{T}>\mathrm{t}$, we have, from (5),

$$
a^{\alpha}\left(\alpha^{\mathrm{t}}\right) \mathrm{q}\left(\alpha^{\mathrm{t}}\right)=\sum_{\mathrm{r}=\mathrm{t}+1}^{\mathrm{T}} \sum_{\alpha^{\mathrm{r}} \mid \alpha^{\mathrm{t}}} \mathrm{a}^{\alpha}\left(\alpha^{\mathrm{r}}\right) \mathrm{p}\left(\alpha^{\mathrm{r}}\right) \mathrm{x}\left(\alpha^{\mathrm{r}} \mid \alpha^{\mathrm{t}}\right)+\sum_{\alpha^{\mathrm{T}} \mid \alpha^{\mathrm{t}}} \mathrm{a}^{\alpha}\left(\alpha^{\mathrm{T}}\right) \mathrm{q}\left(\alpha^{\mathrm{T}}\right) \mathrm{e}\left(\alpha^{\mathrm{T}} \mid \alpha^{\mathrm{t}}\right)
$$


As $T$ approaches infinity, the first term on the right approaches $a^{\alpha}\left(\alpha^{t}\right) f^{\alpha}\left(\alpha^{t}, a^{\alpha}\right)$. Since the second term on the right is nonnegative, we get Theorem 1A. For an asset with finite maturity, the second term on the right becomes constantly zero after $\mathrm{T}$ is sufficiently large, and (16) implies Theorem 1B. From the definition of fundamental value, we have:

$$
a^{\alpha}\left(\alpha^{t}\right) f^{\alpha}\left(\alpha^{t}, a^{\alpha}\right)=\sum_{\alpha^{t+1} \mid \alpha^{t}} a^{\alpha}\left(\alpha^{t+1}\right) p\left(\alpha^{t+1}\right) d\left(\alpha^{t+1}\right)+\sum_{\alpha^{t+1} \mid \alpha^{t}} a^{\alpha}\left(\alpha^{t+1}\right) f^{\alpha}\left(\alpha^{t+1}, a^{\alpha}\right) b\left(\alpha^{t+1}\right)
$$

Theorem 1C follows from subtracting (17) from (5). Q.E.D.

Theorem 1A says that asset price is never lower than the fundamental value under any state price process of any agent, or there can be no negative bubbles. This implies that the fundamental value has to be finite. Theorem $1 \mathrm{~B}$ says that no finite maturity asset can have a bubble. This implies that the fundamental value of a finite maturity asset is the under any state price process same for any agent. Theorem 1C says that a bubble must be self-perpetuating in the sense that it satisfies a generalized martingale relation.

Theorem 1B does not contradict either Allen, Morris and Postlewaite (1993) or Allen and Gorton (1993), because these studies make use of short-sale constraints. In the presence of short-sale constraints, one can still define bubble, as the studies cited above do, as the difference between price and fundamental value. However, under this definition a bubble could be a one-period phenomenon representing the excess of price over one-period return, an excess not possible when short sales are allowed. In contrast, $\mathrm{Yu}$ (1998) defines bubble as the difference between the price net all such excesses and the fundamental value. Under this more strict definition, bubbles are necessarily self-perpetuating, and the difference between the prices and the fundamental values in the studies cited above do not qualify as bubbles. 
Unlike negative and finite bubbles, positive bubbles cannot be ruled out by arbitrage arguments alone. In the homogeneous information case, general equilibrium arguments have been used to rule out positive bubbles since at least the work of Brock (1979). The basic conclusion of this approach is that, because of their self-perpetuating property, the existence of bubbles may make market clearing impossible on remote future dates. Santos and Woodford (1997) use this approach in a general setting and show that bubbles can be ruled out on any asset with positive supply if the economy's aggregate endowment has a finite present value. In what follows, we show that similar ideas can be applied to a diverse information setting. Specifically, if agents are impatient and the present value of the aggregate endowment is finite under some agent $\alpha$ 's state price process $\left\{\mathrm{a}^{\alpha}\right\}$, then agent $\alpha$ does not perceive a bubble under $\left\{a^{\alpha}\right\}$ on any asset with positive supply.

We will let $\alpha$ be the agent whose state price process $\left\{a^{\alpha}\right\}$ is used to calculate values and use $\beta$ as the index for agents. While diverse information makes it possible for agents to have "private" state price processes, any state price process of any agent must be consistent with the commonly observed prices and returns. As a result, each $\left\{\mathrm{a}^{\alpha}\right\}$ can still help measure the values pertaining to all agents or the whole economy. To avoid certain complications, we will maintain the assumption that aggregate endowment is adapted to every individual information tree, and aggregate initial asset endowment is adapted to every individual partition at $\mathrm{t}=0$.

Agent $\beta$ is endowed with $\widetilde{Z}^{\beta}\left(\beta^{0}\right)$ of assets at node $\beta^{0}$, which may have both positive and negative elements. We obviously have, for any $s^{0} / \beta^{0}, \widetilde{Z}^{\beta}\left(s^{0}\right)=\widetilde{Z}^{\beta}\left(\beta^{0}\right)$. Aggregate asset 
endowment at $s^{0}$, which is the asset supply at $s^{0}$, is $\widetilde{Z}\left(s^{0}\right)=\sum_{\beta} \widetilde{Z}^{\beta}\left(s^{0}\right)$. We assume that $\tilde{Z}\left(s^{0}\right)$ is nonnegative and adapted to every individual partition at $\mathrm{t}=0$. There is no asset endowment at any node with $t \neq 0$. While we do not require that $q$ is strictly positive, we assume that agents never dispose of assets outside the market. With this assumption, asset supply at arbitrary node $s^{t}$ is given by $\widetilde{Z}\left(s^{t}\right)=e\left(s^{t} \mid s^{0}\right) \widetilde{Z}\left(s^{0}\right)$. Because $e\left(s^{t} \mid s^{0}\right)$ is nonnegative and adapted to each $\mathrm{N}^{\beta}, \tilde{\mathrm{Z}}\left(\mathrm{s}^{\mathrm{t}}\right)$, like $\widetilde{\mathrm{Z}}\left(\mathrm{s}^{0}\right)$, is nonnegative and adapted to each $\mathrm{N}^{\beta}$.

Agent $\beta$ has a nonnegative good endowment process $\left\{\omega^{\beta}\right\}$. Aggregate good endowment at an arbitrary node $s^{t}$ is given by $\omega\left(s^{t}\right)=\sum_{\beta} \omega^{\beta}\left(s^{t}\right)$. We assume that $\{\omega\}$ is adapted to each $N^{\beta}$. The supply of goods at $s^{t}(t \neq 0)$ is given by $\widetilde{\omega}\left(s^{t}\right)=\omega\left(s^{t}\right)+x\left(s^{t} \mid s^{0}\right) \widetilde{Z}\left(s^{0}\right)$ and is nonnegative and adapted to each $N^{\beta}$. For each $s^{0}$, we have $\widetilde{\omega}\left(s^{0}\right)=\omega\left(s^{0}\right)$.

We assume that the preferences of any household are increasing in the following sense: more of any good at any node is always weakly preferred, and at each node there is at least one good more of which is strictly preferred.

Let $c^{\beta}$ be a typical nonnegative consumption process for agent $\beta$. For any $\beta^{t} \in \mathrm{N}^{\beta}$, we can write $c^{\beta}=\left(c_{-}^{\beta}\left(\beta^{t}\right), c^{\beta}\left(\beta^{t}\right), c_{+}^{\beta}\left(\beta^{t}\right)\right)$, where $c_{-}^{\beta}\left(\beta^{t}\right)$ denotes the coordinates of $c^{\beta}$ indicating consumption at nodes other than those on the subtree starting at $\beta^{t}, c^{\beta}\left(\beta^{t}\right)$ denotes the coordinates of $c^{\beta}$ indicating consumption at $\beta^{t}$, and $c_{+}^{\beta}\left(\beta^{t}\right)$ denotes the coordinates of $c^{\beta}$ indicating consumption at nodes on the subtree starting at $\beta^{t}$ other than $\beta^{t}$ itself. According to this notation, $c^{\beta}\left(\beta^{t}\right)$ represents present consumption, $c_{+}^{\beta}\left(\beta^{t}\right)$ represents future consumption, both with reference to $\beta^{t}$, while $c_{-}^{\beta}\left(\beta^{t}\right)$ represents the past consumption with reference to $\beta^{t}$ as 
well as the present and future consumption not on the subtree starting at $\beta^{\mathrm{t}}$. The trade-off between $c^{\beta}\left(\beta^{t}\right)$ and $c_{+}^{\beta}\left(\beta^{t}\right)$ therefore indicates the degree of impatience (with reference to $\beta^{t}$ ) in agent $\beta$ 's preferences.

Let $\succ^{\beta}$ represent agent $\beta$ 's strict preference relation. To make a precise definition of impatience, we use the aggregate good supply $\widetilde{\omega}\left(\beta^{t}\right)$ to describe the alternative consumption at $\beta^{\mathrm{t}}$, and a discount factor to describe the alternative future consumption with reference to $\beta^{\mathrm{t}}$. For given $\left\{\tilde{\omega}\left(\beta^{t}\right)\right\}$, we say agent $\beta$ is impatient if there exists $0 \leq \gamma^{\beta}<1$ such that for any $\beta^{t} \in N^{\beta}$

$$
\left(c_{-}^{\beta}\left(\beta^{t}\right), c^{\beta}\left(\beta^{t}\right)+\widetilde{\omega}\left(\beta^{t}\right), \gamma c_{+}^{\beta}\left(\beta^{t}\right)\right) \succ^{\beta} c^{\beta}
$$

for all consumption processes satisfying $c^{\beta} \leq \widetilde{\omega}$ and all $\gamma \geq \gamma^{\beta}$. This definition depends on $\left\{\widetilde{\omega}\left(\beta^{t}\right)\right\}$, which is determined by good and asset endowments, and so impatience is a joint assumption of preferences and endowments. This impatience assumption, which is also used by Magill and Quinzii (1994) and Levine and Zame (1996), is satisfied by all preferences that are represented by continuous, stationary, recursive utility functions; for more details, see Santos and Woodford (1994).

For any impatient agent $\beta$, any optimal portfolio-consumption plan must satisfy, at any $\beta^{t} \in N^{\beta}$

$$
\left(1-\gamma^{\beta}\right) q\left(\beta^{t}\right) z^{\beta}\left(\beta^{t}\right)<p\left(\beta^{t}\right) \tilde{\omega}\left(\beta^{t}\right)
$$

This is because if (19) were not true at some $\beta^{t}$, it would be feasible to realize the consumption process $\left(c_{-}^{\beta}\left(\beta^{t}\right), c^{\beta}\left(\beta^{t}\right)+\widetilde{\omega}\left(\beta^{t}\right), \gamma^{\beta} c_{+}^{\beta}\left(\beta^{t}\right)\right)$ by liquidating the fraction $1-\gamma^{\beta}$ of the portfolio held at $\beta^{\mathrm{t}}$, using the proceeds to purchase $\widetilde{\omega}\left(\beta^{\mathrm{t}}\right)$ for consumption, and trading and 
holding the fraction $\gamma^{\beta}$ of the original amounts of assets and consuming the fraction $\gamma^{\beta}$ of the original consumption at all the successor nodes of $\beta^{t}$. By the impatience assumption, $\left(c_{-}^{\beta}\left(\beta^{t}\right)\right.$, $\left.c^{\beta}\left(\beta^{t}\right)+\widetilde{\omega}\left(\beta^{t}\right), \gamma^{\beta} c_{+}^{\beta}\left(\beta^{t}\right)\right)$ is strictly preferred to $c^{\beta}$, and so $c^{\beta}$ could not be optimal.

Agent $\beta$ chooses, for each node $\beta^{t} \in \mathrm{N}^{\beta}$, portfolio $\mathrm{z}^{\beta}\left(\beta^{t}\right)$ and nonnegative consumption $c^{\beta}\left(\beta^{t}\right)$. For any $\beta^{t} \in N^{\beta}$, the constraints it faces are:

$$
\begin{aligned}
& p\left(\beta^{t}\right) c^{\beta}\left(\beta^{t}\right)+q\left(\beta^{t}\right) Z^{\beta}\left(\beta^{t}\right)=p\left(\beta^{t}\right) \omega^{\beta}\left(\beta^{t}\right)+\left[p\left(\beta^{t}\right) d\left(\beta^{t}\right)+q\left(\beta^{t}\right) b\left(\beta^{t}\right)\right] Z^{\beta}\left(\beta^{t}-1\right) \\
& q\left(\beta^{t}\right) Z^{\beta}\left(\beta^{t}\right) \geq-B^{\beta}\left(\beta^{t}\right)
\end{aligned}
$$

The left side of (20a) represents expenditure, while the right side represents income. We have written (20a) as an equality on account of increasing preferences. For any $\beta^{0}$, the last term on the right of (20a) takes the special form of $q\left(\beta^{0}\right) \tilde{Z}\left(\beta^{0}\right)$. $B^{\beta}\left(\beta^{t}\right)$ in (20b) is the nonnegative borrowing limit for agent $\beta$ at node $\beta^{\mathrm{t}}$. We assume that households treat the borrowing limits as given data. In order for the agent optimization problem to be well-defined, borrowing limits have to at least rule out the Ponzi scheme. For our purposes, a specific description of borrowing limits is not needed.

Consider the processes $\left\{\mathrm{p}\left(\mathrm{m}^{\mathrm{t}}\right), \mathrm{q}\left(\mathrm{m}^{\mathrm{t}}\right), \mathrm{c}^{\beta}\left(\beta^{\mathrm{t}}\right), \mathrm{Z}^{\beta}\left(\beta^{\mathrm{t}}\right)\right\}$. If they represent an Arrow-Radner equilibrium, they must satisfy the following necessary conditions:

(i) For each $\beta,\left\{c^{\beta}\left(\beta^{t}\right), Z^{\beta}\left(\beta^{t}\right)\right\}$ are optimal under (20).

(ii) For each st,

$$
\begin{aligned}
& \mathrm{p}\left(\mathrm{s}^{\mathrm{t}}\right) \geq 0, \mathrm{q}\left(\mathrm{s}^{\mathrm{t}}\right) \geq 0 \\
& \sum_{\beta} \mathrm{c}^{\beta}\left(\mathrm{s}^{\mathrm{t}}\right) \leq \widetilde{\omega}\left(\mathrm{s}^{\mathrm{t}}\right)
\end{aligned}
$$




$$
\begin{aligned}
& p\left(s^{t}\right)\left[\sum_{\beta} c^{\beta}\left(s^{t}\right)-\widetilde{\omega}\left(s^{t}\right)\right]=0 \\
& \sum_{\beta} Z^{\beta}\left(s^{t}\right)=\widetilde{Z}\left(s^{t}\right)
\end{aligned}
$$

(22a) is the economy-wide resource constraint. (22b), which asserts that any good not fully used up must have zero price, follows from the fact that all goods are fully owned by households, and so given the increasing preferences, no household will give up any good that can be sold at a positive price.

Without loss of generality, we focus on the possibility of bubbles at date 0 . The following theorem resembles Theorem 3.3 of Santos and Woodford (1997).

Theorem 2: Suppose all households are impatient. Then in any Arrow-Radner equilibrium in which $v_{\omega}\left(\alpha^{0}, a^{\alpha}\right)<+\infty$ for any $\alpha^{0}$ under some state price process $\left\{a^{\alpha}\right\}$ for agent $\alpha, f_{\mathrm{j}}^{\alpha}\left(\alpha^{0}, a^{\alpha}\right)=q_{\mathrm{j}}\left(\alpha^{0}\right)$ for any $\alpha^{0}$ and any asset $j$ at $\alpha^{0}$ with positive supply.

Proof: For any $\alpha^{\mathrm{t}}$, assign a number $\mathrm{g}^{\alpha}\left(\mathrm{s}^{\mathrm{t}}\right)$ to each $\mathrm{s}^{\mathrm{t}} / \alpha^{\mathrm{t}}$ such that

$$
\sum_{s^{t} / \alpha^{t}} g^{\alpha}\left(s^{t}\right)=a^{\alpha}\left(\alpha^{t}\right)
$$

We will use $\left\{g^{\alpha}\right\}$ to "value" variables defined on N. For our purposes, $\left\{g^{\alpha}\right\}$ can be regarded as a purely mechanical device.

Let $\bar{\gamma}$ be the largest of $\gamma^{\beta}$ s. By (19), for any $\beta$ and any s ${ }^{\mathrm{t}}$, we have:

$$
(1-\bar{\gamma}) \mathrm{q}\left(\mathrm{s}^{\mathrm{t}}\right) \mathrm{Z}^{\beta}\left(\mathrm{s}^{\mathrm{t}}\right)<\mathrm{p}\left(\mathrm{s}^{\mathrm{t}}\right) \widetilde{\omega}\left(\mathrm{s}^{\mathrm{t}}\right)
$$

Summing (25) over $s^{t}$ using $g^{\alpha}\left(s^{t}\right)$ 's as weights, we get:

$$
\sum_{s^{t}} g^{\alpha}\left(s^{t}\right) q\left(s^{t}\right) Z^{\beta}\left(s^{t}\right)<\frac{1}{1-\bar{\gamma}} \sum_{s^{t}} g^{\alpha}\left(s^{t}\right) p\left(s^{t}\right) \widetilde{\omega}\left(s^{t}\right)
$$




$$
\begin{aligned}
& =\frac{1}{1-\bar{\gamma}} \sum_{\alpha^{t}} \sum_{s^{t} / \alpha^{t}} g^{\alpha}\left(s^{t}\right) p\left(s^{t}\right) \tilde{\omega}\left(s^{t}\right) \\
& \left.=\frac{1}{1-\bar{\gamma}} \sum_{\alpha^{t}}\left[\sum_{s^{t} / \alpha^{t}} g^{\alpha}\left(s^{t}\right)\right] p\left(\alpha^{t}\right) \tilde{\omega}\left(\alpha^{t}\right) \quad \text { (because } p \text { and } \tilde{\omega} \text { are adapted to } N^{\alpha}\right) \\
& =\frac{1}{1-\bar{\gamma}} \sum_{\alpha^{t}} a^{\alpha}\left(\alpha^{t}\right) p\left(\alpha^{t}\right) \widetilde{\omega}\left(\alpha^{t}\right) \quad(b y(24))
\end{aligned}
$$

Let $\varepsilon>0$ be an arbitrary positive number, and $L$ be the total number of agents. Because $\mathrm{v}_{\omega}\left(\alpha^{0}\right.$, $\left.\mathrm{a}^{\alpha}\right)<+\infty$ for any $\alpha^{0}, \mathrm{v}_{\tilde{\omega}}\left(\alpha^{0}, \mathrm{a}^{\alpha}\right)<+\infty$ for any $\alpha^{0}$. This means there exists $\overline{\mathrm{T}}$ such that, for any $\mathrm{T} \geq \overline{\mathrm{T}}$

$$
\sum_{\alpha^{\mathrm{T}}} \mathrm{a}^{\alpha}\left(\alpha^{\mathrm{T}}\right) \mathrm{p}\left(\alpha^{\mathrm{T}}\right) \tilde{\omega}\left(\alpha^{\mathrm{T}}\right) \leq(1-\bar{\gamma}) \frac{\varepsilon}{\mathrm{L}}
$$

Combining (26) and (27), we have, for any $\beta$ and any $\mathrm{T} \geq \overline{\mathrm{T}}$,

$$
\sum_{s^{T}} g^{\alpha}\left(s^{T}\right) q\left(s^{T}\right) Z^{\beta}\left(s^{T}\right) \leq \frac{\varepsilon}{L}
$$

Define $R\left(\beta^{t}\right)=p\left(\beta^{t}\right) d\left(\beta^{t}\right)+q\left(\beta^{t}\right) b\left(\beta^{t}\right)$. By (18), for any $\beta$ and any $s^{t}$, we have:

$$
p\left(s^{t}\right) c^{\beta}\left(s^{t}\right)+q\left(s^{t}\right) Z^{\beta}\left(s^{t}\right)=p\left(s^{t}\right) \omega^{\beta}\left(s^{t}\right)+R\left(s^{t}\right) Z^{\beta}\left(s^{t}-1\right)
$$

For $\mathrm{t}=0$, the last term of (29) takes the special form of $\mathrm{q}\left(\mathrm{s}^{0}\right) \widetilde{Z}^{\beta}\left(\mathrm{s}^{0}\right)$. Summing (29) $\operatorname{across} s^{t} u \operatorname{sing} g^{\alpha}\left(s^{t}\right)$ 's as weights and summing the resulting equations from $t=0$ to some $\mathrm{T} \geq$ $\overline{\mathrm{T}}$, we get (noting the special form (29) takes for $\mathrm{t}=0$ ):

$$
\begin{aligned}
& \sum_{s^{0}} g^{\alpha}\left(s^{0}\right) q\left(s^{0}\right) \widetilde{Z}^{\beta}\left(s^{0}\right)=\sum_{t=0}^{T} \sum_{s^{t}} g^{\alpha}\left(s^{t}\right)\left[p\left(s^{t}\right) c^{\beta}\left(s^{t}\right)-p\left(s^{t}\right) \omega^{\beta}\left(s^{t}\right)\right]+\sum_{s^{0}} g^{\alpha}\left(s^{0}\right) q\left(s^{0}\right) Z^{\beta}\left(s^{0}\right) \\
& +\sum_{t=1}^{T} \sum_{s^{t}} g^{\alpha}\left(s^{t}\right)\left[q\left(s^{t}\right) Z^{\beta}\left(s^{t}\right)-R\left(s^{t}\right) Z^{\beta}\left(s^{t}-1\right)\right]
\end{aligned}
$$




$$
\begin{aligned}
& =\sum_{t=0}^{T} \sum_{s^{t}} g^{\alpha}\left(s^{t}\right)\left[p\left(s^{t}\right) c^{\beta}\left(s^{t}\right)-p\left(s^{t}\right) \omega^{\beta}\left(s^{t}\right)\right] \\
& +\sum_{t=0}^{T-1} \sum_{s^{t}}\left[g^{\alpha}\left(s^{t}\right) q\left(s^{t}\right) Z^{\beta}\left(s^{t}\right)-\sum_{s^{+1}+1 s^{t}} g^{\alpha}\left(s^{t+1}\right) R\left(s^{t+1}\right) Z^{\beta}\left(s^{t}\right)\right]+\sum_{s^{T}} g^{\alpha}\left(s^{T}\right) q\left(s^{T}\right) Z^{\beta}\left(s^{T}\right)
\end{aligned}
$$

The left side of (30) can be written as:

$$
\sum_{s^{0}} g^{\alpha}\left(s^{0}\right) q\left(s^{0}\right) \tilde{Z}^{\beta}\left(s^{0}\right)=\sum_{\alpha^{0}} a^{\alpha}\left(\alpha^{0}\right) q\left(\alpha^{0}\right) \tilde{Z}^{\beta}\left(\alpha^{0}\right)
$$

When summed over $\beta$, by market clearing condition (23), the right side of (31) becomes

$$
\sum_{\alpha^{0}} \mathrm{a}^{\alpha}\left(\alpha^{0}\right) \mathrm{q}\left(\alpha^{0}\right) \tilde{\mathrm{Z}}\left(\alpha^{0}\right)
$$

Define $\mathrm{f}^{\mathrm{T}, \alpha}\left(\alpha^{0}, \mathrm{a}^{\alpha}\right)$ as the present value vector of the dividend processes truncated at $\mathrm{T}$.

We will sum each of the three terms on the right of (30) over $\beta$. For the first term, we have:

$$
\begin{aligned}
& \sum_{\beta} \sum_{t=0}^{T} \sum_{s^{t}} g^{\alpha}\left(s^{t}\right)\left[p\left(s^{t}\right) c^{\beta}\left(s^{t}\right)-p\left(s^{t}\right) \omega^{\beta}\left(s^{t}\right)\right]=\sum_{t=0}^{T} \sum_{s^{t}} g^{\alpha}\left(s^{t}\right) p\left(s^{t}\right)\left[\sum_{\beta} c^{\beta}\left(s^{t}\right)-\omega\left(s^{t}\right)\right] \\
& \left.=\sum_{\mathrm{t}=1}^{\mathrm{T}} \sum_{\mathrm{s}^{0}} \sum_{\mathrm{s}^{\mathrm{t}} \mid \mathrm{s}^{0}} \mathrm{~g}^{\alpha}\left(\mathrm{s}^{\mathrm{t}}\right) \mathrm{p}\left(\mathrm{s}^{\mathrm{t}}\right) \mathrm{x}\left(\mathrm{s}^{\mathrm{t}} \mid \mathrm{s}^{0}\right) \tilde{\mathrm{Z}}\left(\mathrm{s}^{0}\right) \quad \text { (by (22b) and the definition of } \widetilde{\omega}\right) \\
& \left.=\sum_{\mathrm{t}=1}^{\mathrm{T}} \sum_{\alpha^{0}} \sum_{\mathrm{s}^{0} / \alpha^{0}} \sum_{\mathrm{s}^{\mathrm{t}} \mathrm{s}^{0}} \mathrm{~g}^{\alpha}\left(\mathrm{s}^{\mathrm{t}}\right) \mathrm{p}\left(\mathrm{s}^{\mathrm{t}}\right) \mathrm{x}\left(\mathrm{s}^{\mathrm{t}} \mid \alpha^{0}\right) \tilde{Z}\left(\alpha^{0}\right) \quad \text { (because } \mathrm{x} \text { and } \tilde{Z} \text { are adapted to } \mathrm{N}^{\alpha}\right) \\
& =\sum_{\mathrm{t}=1}^{\mathrm{T}} \sum_{\alpha^{0}} \sum_{\alpha^{\mathrm{t}} \mid \alpha^{0}} \sum_{\mathrm{s}^{\mathrm{t}} / \alpha^{\mathrm{t}}} \mathrm{g}^{\alpha}\left(\mathrm{s}^{\mathrm{t}}\right) \mathrm{p}\left(\alpha^{\mathrm{t}}\right) \mathrm{x}\left(\alpha^{\mathrm{t}} \mid \alpha^{0}\right) \tilde{Z}\left(\alpha^{0}\right) \quad \text { (because } \sum_{\mathrm{s}^{0} / \alpha^{0}} \sum_{\mathrm{s}^{\mathrm{t}} \mathrm{s}^{0}} \text { and } \\
& \sum_{\alpha^{t} \mid \alpha^{0}} \sum_{s^{t} / \alpha^{t}} \text { sum over the same s } s^{t, s} \text { and } \mathrm{x} \text { is adapted to } \mathrm{N}^{\alpha} \text { ) } \\
& =\sum_{\mathrm{t}=1}^{\mathrm{T}} \sum_{\alpha^{0}} \sum_{\alpha^{\mathrm{t}} \mid \alpha^{0}} \mathrm{a}^{\alpha}\left(\alpha^{\mathrm{t}}\right) \mathrm{p}\left(\alpha^{\mathrm{t}}\right) \mathrm{x}\left(\alpha^{\mathrm{t}} \mid \alpha^{0}\right) \tilde{Z}\left(\alpha^{0}\right) \quad(\text { by (24)) }
\end{aligned}
$$


$=\sum_{\alpha^{0}} \mathrm{a}^{\alpha}\left(\alpha^{0}\right) \mathrm{f}^{\mathrm{T}, \alpha}\left(\alpha^{0}, \mathrm{a}^{\alpha}\right) \tilde{\mathrm{Z}}\left(\alpha^{0}\right) \quad\left(\right.$ by the definition of $\left.\mathrm{f}^{\mathrm{T}, \alpha}\right)$

Summing the second term on the right of (30) for a particular t over $\beta$, we get:

$$
\begin{aligned}
& \sum_{\beta} \sum_{s^{t}}\left[g^{\alpha}\left(s^{t}\right) q\left(s^{t}\right) Z^{\beta}\left(s^{t}\right)-\sum_{s^{t+1} \mid s^{t}} g^{\alpha}\left(s^{t+1}\right) R\left(s^{t+1}\right) Z^{\beta}\left(s^{t}\right)\right] \\
& =\sum_{s^{t}}\left[g^{\alpha}\left(s^{t}\right) q\left(s^{t}\right)-\sum_{s^{+1+} \mid s^{t}} g^{\alpha}\left(s^{t+1}\right) R\left(s^{t+1}\right)\right] \widetilde{Z}\left(s^{t}\right) \quad \text { (by (23)) } \\
& =\sum_{\alpha^{t}} \sum_{s^{t} / \alpha^{t}}\left[g^{\alpha}\left(s^{t}\right) q\left(\alpha^{t}\right)-\sum_{s^{t+1} \mid s^{t}} g^{\alpha}\left(s^{t+1}\right) R\left(\alpha^{t+1}\right)\right] \tilde{Z}\left(\alpha^{t}\right) \\
& =\sum_{\alpha^{\mathrm{t}}}\left[\mathrm{a}^{\alpha}\left(\alpha^{\mathrm{t}}\right) \mathrm{q}\left(\alpha^{\mathrm{t}}\right)-\sum_{\alpha^{\mathrm{t}+1} \mid \alpha^{\mathrm{t}}} \mathrm{a}^{\alpha}\left(\alpha^{\mathrm{t}+1}\right) \mathrm{R}\left(\alpha^{\mathrm{t}+1}\right)\right] \tilde{Z}\left(\alpha^{\mathrm{t}}\right)=0
\end{aligned}
$$

The last step uses the fact that $\left\{\mathrm{a}^{\alpha}\right\}$ is a state price process.

Summing the last term on the right of (30) over $\beta$ and using (28), we have:

$$
\sum_{\beta} \sum_{\mathrm{s}^{\mathrm{T}}} \mathrm{g}^{\alpha}\left(\mathrm{s}^{\mathrm{T}}\right) \mathrm{q}\left(\mathrm{s}^{\mathrm{T}}\right) \mathrm{Z}^{\beta}\left(\mathrm{s}^{\mathrm{T}}\right) \leq \mathrm{L} \frac{\varepsilon}{\mathrm{L}}=\varepsilon
$$

Combining (30)-(34), we get:

$$
\sum_{\alpha^{0}} a^{\alpha}\left(\alpha^{0}\right)\left[q\left(\alpha^{0}\right)-f^{T, \alpha}\left(\alpha^{0}, a^{\alpha}\right)\right] \widetilde{Z}\left(\alpha^{0}\right) \leq \varepsilon
$$

Because $a^{\alpha}\left(\alpha^{0}\right)$ is strictly positive and $q\left(\alpha^{0}\right) \geq f^{\alpha}\left(\alpha^{0}, a^{\alpha}\right) \geq f^{T, \alpha}\left(\alpha^{0}, a^{\alpha}\right)$, each term on the left of (35) is nonnegative. If $\mathrm{q}_{\mathrm{j}}\left(\alpha^{0}\right)>\mathrm{f}_{\mathrm{j}}^{\alpha}\left(\alpha^{0}, \mathrm{a}^{\alpha}\right)$ for an asset $\mathrm{j}$ with positive supply, then the left side has a positive lower bound, and for sufficiently small $\varepsilon$ (35) cannot hold at any T. Q.E.D.

\section{Conclusion}

This paper develops an approach and a framework within which diverse information issues can be analyzed in a general way. The basic conclusion of the paper can be easily 
stated: within our framework, as far as the existence of bubbles is concerned, the market necessarily reveals enough information so that any remaining information diversity does not matter.

\section{References}

Allen, F. and G. Gorton (1993): Churning Bubbles. Review of Economic Studies, 60, 813-36.

Allen, F., S. Morris and A. Postlewaite (1993): Finite Bubbles with Short Sale Constraints and Asymmetric Information. Journal of Economic Theory, 61, 206-29.

Aumann, R. (1976): Agreeing to Disagree. Annals of Statistics, 4, 1236-9.

Brock, W. (1979): An Integration of Stochastic Growth Theory and the Theory of Finance. In General Equilibrium, Growth and Trade, edited by J. Green and J. Scheinkman. Chow, G. (1997): Dynamic Economics: Optimization by the Lagrange Method.

De Long, J., A. Shleifer, L. Summers and R. Waldman (1990): Noise Trader Risk in Financial Markets. Journal of Political Economy, 98, 703-38.

Duffie, D. and C. Huang (1986): Multiperiod Security Markets with Differential Information. Journal of Mathematical Economics, 15, 283-303.

Fudenberg, D. and J. Tirole (1991): Game Theory.

Geanakoplos, J. (1994): Common Knowledge. In Handbook of Game Theory with Economic Applications, vol. 2, edited by R. Aumann and S. Hart.

Levine, D. and W. Zame (1996): Debt Constraints and Equilibrium in Infinite Horizon Economies with Incomplete Markets, Journal of Mathematical Economics, 26, 103-31. 
Magill, M. and M. Quinzii (1994): Infinite Horizon Incomplete Markets, Econometrica, 63, 853-80.

Milgrom, P. (1981): An Axiomatic Characterization of Common Knowledge. Econometrica, 49, 219-22.

Radner, R. (1972): Existence of Equilibrium of Plans, Prices and Price Expectations in a Sequence of Markets. Econometrica, 40, 289-304.

Radner, R. (1979): Rational Expectations Equilibrium: Generic Existence and the Information Revealed by Prices. Econometrica, 47, 655-78.

Ross, S. (1976): The Arbitrage Theory of Capital Asset Pricing. Journal of Economic Theory, 13(3), 341-60.

Santos, M. and M. Woodford (1994): Rational Asset Pricing Bubbles. Discussion paper.

Santos, M. and M. Woodford (1997): Rational Asset Pricing Bubbles. Econometrica, 65, 19-57.

Tirole, J. (1985): Asset Bubbles and Overlapping Generations. Econometrica, 53, 1163-81.

Wang, J. (1993): A Model of Intertemporal Asset Prices Under Asymmetric Information. Review of Economic Studies, 60, 249-82.

Yu, D. (1998): Frictional Arbitrage Valuation. Ph.D. thesis, Princeton University. Zhou, C. (1995): Information, Financial Markets, and Investment. Ph.D. thesis, Princeton University. 